\title{
Semi-permeable layer formation during seed development in Elymus nutans and Elymus sibiricus
}

\author{
Jing Zhou', Yanrong Wang ${ }^{1 *}$, Jason Trethewey ${ }^{2}$ \\ 'State Key Laboratory of Grassland Agro-ecosystems, College of Pastoral Agriculture Science and Technology, Lanzhou University, P.0. Box 61, Lanzhou 730020 , China \\ ${ }^{2}$ Agresearch, Lincoln Research Centre, Private Bag 4749, Christchurch 8140, New Zealand
}

\section{Abstract}

The semi-permeable layer is a layer in the seeds of certain plants that restricts or impedes the exchange of the solute while allowing the permeability of internal and external water and gas, which is valuable protection to sustain the health and secure the growth, development and germination. In this study, the formation time and location of the semi-permeable layer in seed coats of Elymus nutants (Griseb.) and Elymus sibiricus (L.) were investigated. The experimental seed materials were gathered in the field from the flowering to seed maturation. The light microscopy and transmission electron microscopy for lanthanum nitrate identification were used to examine the characteristics of pericarp, seed coat and nucellus. The results showed that the semi-permeable layer was identified as the position, which can inhibit the penetration of the lanthanum, and it was checked as an amorphous membrane located at the outermost layer of the seed coat that is firmly attached to the seed coat. With seed development, the cells had differentiated and some parts of the ovary and the outer integument had disappeared. The semi-permeable layer originated from the outer layer of the inner integument, which was the original form of the seed coat. It can be stained by the Sudan III and clearly distinguished from other parts of the seed. The formation time of the semi-permeable layer in both species was nearly at 10 to 12 days post-anthesis (dpa), whereas seed physiological maturity was 24 to 26 dpa.

Keywords: semi-permeable layer, seed coat, seed development, TEM, Elymus nutans, Elymus sibiricus

\section{Introduction}

The seed coat or testa is the protective outer covering surrounding the plant embryo [1]. The seed coat has several functions including the protection of the embryo in the ripe seed from mechanical damage and pathogen attack and the supply of nutrients during seed development [2]. In some species the seed coat may have a semi-permeable layer allowing water uptake and gas exchange, while restricting or preventing solute transport [3-6]. The semi-permeable layer is an important structure for restricting the penetration of toxic solutes into embryos during imbibition from the soil [7] and may also play a role in water storage by holding a sheet of water adjacent to the embryo and thereby protecting the mature embryo against desiccation [8]. At the same time, this layer surrounding the embryo acts as a barrier to apoplastic permeability and radicle emergence [9]. In addition, seed quality testing studies have

\footnotetext{
* Corresponding author. Email: yrwang@lzu.edu.cn

Handling Editor: Elżbieta Bednarska-Kozakiewicz
}

This is an Open Access digital version of the article distributed under the terms of the Creative Commons Attribution 3.0 License (creativecommons.org/licenses/by/3.0/), which permits redistribution, commercial and non-commercial, provided that the article is properly cited. shown that the existence of semi-permeable layer could decrease the feasibility of testing method, based on the tetrazolium salt or conductivity [10-13]. Therefore, the semi-permeable layer is valuable protection to sustain the health and secure the growth, development, germination, and quality testing of seeds [14].

The presence of a semi-permeable layer can inhibit the infiltration of solutes into the internal seed. For example, tetrazolium chloride, which is used for vital staining, did not penetrate into the inner seed coat of watermelon (Citrullus vulgaris Schrad. ex Eckl. \& Zeyh.) [10], and also was not able to infiltrate the seed coat of several vegetable seeds [4]. In addition, the water-soluble heavy metal lanthanum ion accumulated in the suberin-rich inner seed coat adjacent to the endosperm in tomato (Solanum lycopersicum L.) and pepper (Capsicum annuum L.) [15,16]. Castor (Ricinus communis L.) and switchgrass (Panicum virgatum L.) were impermeable to fluorescent tracers, indicating the presence of a semi-permeable barrier surrounding the embryo [17]. Also, cucumber (Cucumis sativus L.) and muskmelon (Cucumis melo L.) seeds had lipids and callose in their semi-permeable layers $[18,19]$. In many grass species this layer embedded with cutin or suberin in the caryopsis integuments restricts solute diffusion [20] such as barley (Hordeum vulgare L.) [21], Lolium perenne (L.) [22] and Johnsongrass (Sorghum halepensis L.) [23].

While the location and chemical composition of semipermeable membranes in the seeds of many species have been examined, information on the anatomy and timing of the layer formation is limited. In barley, the integumentary system was 
the seat of semi-permeable properties [21], while in corn (Zea mays L.), the suberized semi-permeably layer was also derived from the inner integument [24]. Yim and Bradford [19] had demonstrated that the semi-permeability of the muskmelon endosperm envelope was caused by the outer walls of the endosperm cells at 40 days post-anthesis (dpa). In cucumber seeds at $45 \mathrm{dpa}$, the epidermis of the multilayered nucellus formed the semi-permeable layer [18]. In Sudan grass (Sorghum sudanens Piper.) layer formation was observed at $16 \mathrm{dpa}$ [25].

Elymus nutants (Griseb.) and Elymus sibiricus (L.) are perennial grasses, which have caryopses as propagation units. The caryopsis consists of a single seed fused with the wall of ripened ovary (pericarp), so the term "caryopsis coat" was usually used to define the combined pericarp, seed coat and nucellus [26]. The two investigative grasses are widely distributed in the Tibet and northern China [27] and are characterized by a high tolerance to the stringent conditions of sharp continental climate [28]. These species have been selected as forage cultivars for their adaptation and forage quality, and widely applied in re-vegetation champaigns [29]. Previous research has demonstrated that E. nutans and E. sibiricus possessed a semi-permeable layer, which greatly inhibited electrolyte leakage and tetrazolium ion uptake [14]. However, our knowledge of the formation time and location of semi-permeable membrane is still lacking. The aim of the study was to investigate the main developmental process in the seed coat after fertilization, and try to definitude the specific formation time and location of the semi-permeable layer in $E$. nutans and E. sibiricus.

\section{Material and methods}

\section{Plant material}

The seed development of two forage species (E. nutans and E. sibiricus) was conducted in Gannan prairie, Gansu province, China $\left(102^{\circ} 31^{\prime} \mathrm{E}, 35^{\circ} 12^{\prime} \mathrm{N}\right)$, from July to August 2009 . Sample spikelets were individually tagged at the flowering stage.

\section{Seed collection and fixation}

Tagged spikelets $(n=50)$ were harvested at 2-days interval up to $30 \mathrm{dpa}$ for each species. At each 2-day interval, the palea and lemma from one seed were removed, and the "naked" seed was then fixed at $4^{\circ} \mathrm{C}$ for $24 \mathrm{~h}$ in $4 \%$ glutaraldehyde in phosphate buffer ( $25 \mathrm{mM}, \mathrm{pH} 6.8$ ). The remaining seeds were weighed and air-dried.

\section{Light microscopy (LM) and transmission electron microscopy (TEM)}

The fixed samples were rinsed with PBS (0.1 mol/L, pH 7.2) three times for 10 min each time and dehydrated by alcohol gradient, once with $15 \%, 30 \%, 50 \%, 70 \%$, and $95 \%$ and twice with $100 \%$. The segment of caryopsis coat with subtending endosperm tissue was carefully removed with a razor blade to approximately $1 \mathrm{~mm}^{3}$ and embedded in Technovit 7100 according to described by Kuroiwa [30]. The sections used for LM $(1 \mu \mathrm{m})$ were cut using a semi-thin slices machine (KD202B, LTIE, Shanghai, China), dried and flattened on a glass slide, and stained with $0.2 \%$ Sudan III in $70 \%$ ethanol and $0.05 \%$ aniline blue in $0.1 \mathrm{M}$ phosphate buffer ( $\mathrm{pH}$ 8.2) for approximately 10 min as described by Yim and Bradford [19]. The structure of the caryopsis coat was examined and photos were taken using the compound microscope (Eclipse E 100, Nikon, Toyko, Japan).
The dried seeds were first pre-immersed in distilled water for $24 \mathrm{~h}$ at $20^{\circ} \mathrm{C}$ and then placed intact seeds into vials containing $2 \%(\mathrm{w} / \mathrm{v})$ lanthanum nitrate followed by incubation at $20^{\circ} \mathrm{C}$ for $24 \mathrm{~h} \mathrm{[4]}$. The incubated segments were fixed for 24 hour in $4 \%$ glutaraldehyde in phosphate buffer ( $25 \mathrm{mM}, \mathrm{pH} 6.8)$, and ultrastructural investigation of the seed were prepared as described by Zheng [31] and Sulborska [32]. After rinsing twice with phosphate buffered saline (PBS, $0.1 \mathrm{~mol} / \mathrm{L}, \mathrm{pH}$ 7.2 ), the segments were post-fixed for 24 hours in $1 \%(\mathrm{w} / \mathrm{v})$ osmium tetroxide and again rinsed twice with PBS and then were dehydrated. The vials containing the specimens were kept in ice throughout fixation and dehydration. Following dehydration, the specimens were vacuum-infiltrated and embedded in epon812 epoxy resin for TEM and cut into slices $90 \mathrm{~nm}$ thick with an ultra microtome (LKD-2088, Ultrotom V, Bromma, Sweden). The sections were stained with lead citrate and uranyl acetate and were observed and photographed under TEM (JEM-1230, JEOL, Tokyo, Japan). The semi-permeable layer was identified as the structure of the seed if it prevented the penetration of lanthanum.

\section{Seed germination, weight and moisture content}

Seed was tested for germination on four replicates of 50 seeds for each development seed samples at $25^{\circ} \mathrm{C}$ according to standardized methodology (GB/T 2930.4-2001) [33]. Thousand seed weight was calculated from the average weight of eight replicates of 100 seeds and transformed to thousand seed weight. Seed moisture content was determined using the high-constant-temperature oven method prescribed by the International Seed Testing Association (ISTA) [34].

\section{Electrical conductivity and imbibition rate}

The electrical conductivity test was performed using three replicates of 50 seeds from seed sample at different developmental stages with a DST-A conductivity meter (DST-A, AIP, Tianjin, China). Results were calculated according to Hampton and TeKrony [35] and expressed in $\mu \mathrm{cm}^{-1} \mathrm{~g}^{-1}$. Each replicate was weighed and transferred to $100 \mathrm{~mL}$ distilled water, stirred, covered and held at $20^{\circ} \mathrm{C}$ for $24 \mathrm{~h}$. The conductivity was measured $24 \mathrm{~h}$ later and seeds were surface dried and weighted. The imbibition rate was expressed as the wet weight minus the dry weight, divided by the dry weight.

\section{Statistical analyses}

Statistical analyses were performed using the Statistical program SPSS 16.0 (IBM Corp. Armonk, New York, USA). Analysis of variance with LSD was performed to rank the quality of the seed samples, and an arcsine transformation was applied to the percentages prior to analysis.

\section{Results}

\section{The anatomical structure of the semi-permeable layer formation}

Development of the E. nutans caryopsis coat from 2 dpa to full maturity is shown in Fig. 1. At 2 dpa, a small nucellus and integument cells were arranged tightly with large numbers of ovary cells present (Fig. 1a). This stage included three layers of outer integument and two layers of inner integument and a thin-walled cuboidal outer layer of nucellus connected to the other nucellus. With seed development, the cells had differentiated and some parts of the ovary had disappeared. The 

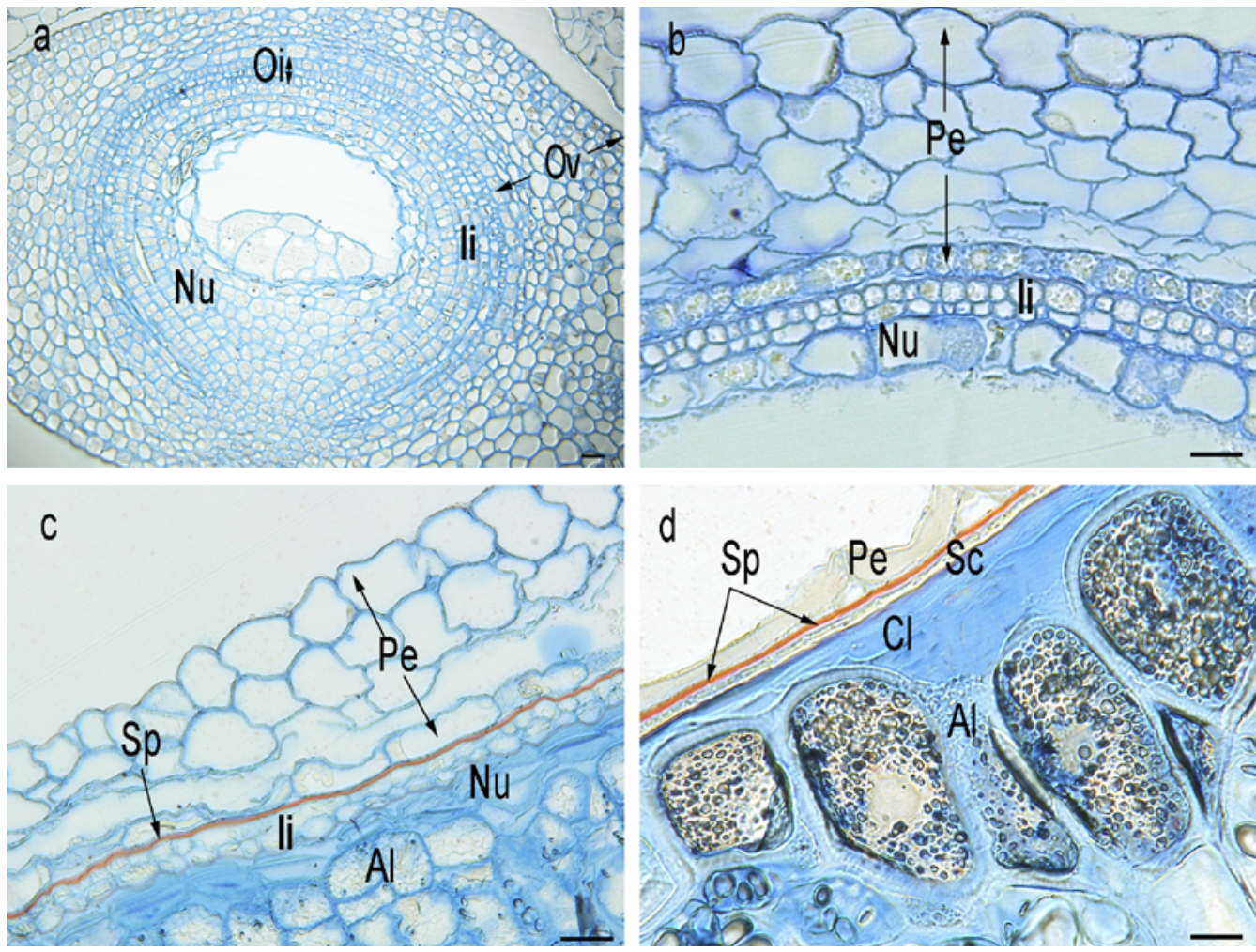

Fig. 1 LM images showing anatomical structure of cross-sections of E. nutans seed coat during seed development from 2 dpa to full maturity. a The whole ovary included ovary wall (Ov), outer integument (Oi), inner integument (Ii) and nucellus (Nu) at 2 dpa. b The section of ovary at 8 dpa with nucellus cells ( $\mathrm{Nu}$ ) and two layers of inner integument (Ii) and the pericarp (Pe). $\mathbf{c}$ The semi-permebale layer (Sp) had formed and was stained by the Sudan III at $12 \mathrm{dpa}$. Remaining nucellus $(\mathrm{Nu})$ were stained by the aniline blue. $\mathbf{d}$ At $26 \mathrm{dpa}$, the seed coat (Sc) had formed and aleurone layer ( $\mathrm{Al})$ was evident. The main structure of the seed included the pericarp (Pe), the semi-permeable layer (Sp), the seed coat (Sc), the callose layer $(\mathrm{Cl})$ and the aleurone layer (Al). Scale bars: a-c $20 \mu \mathrm{m} ; \mathbf{d} 10 \mu \mathrm{m}$.
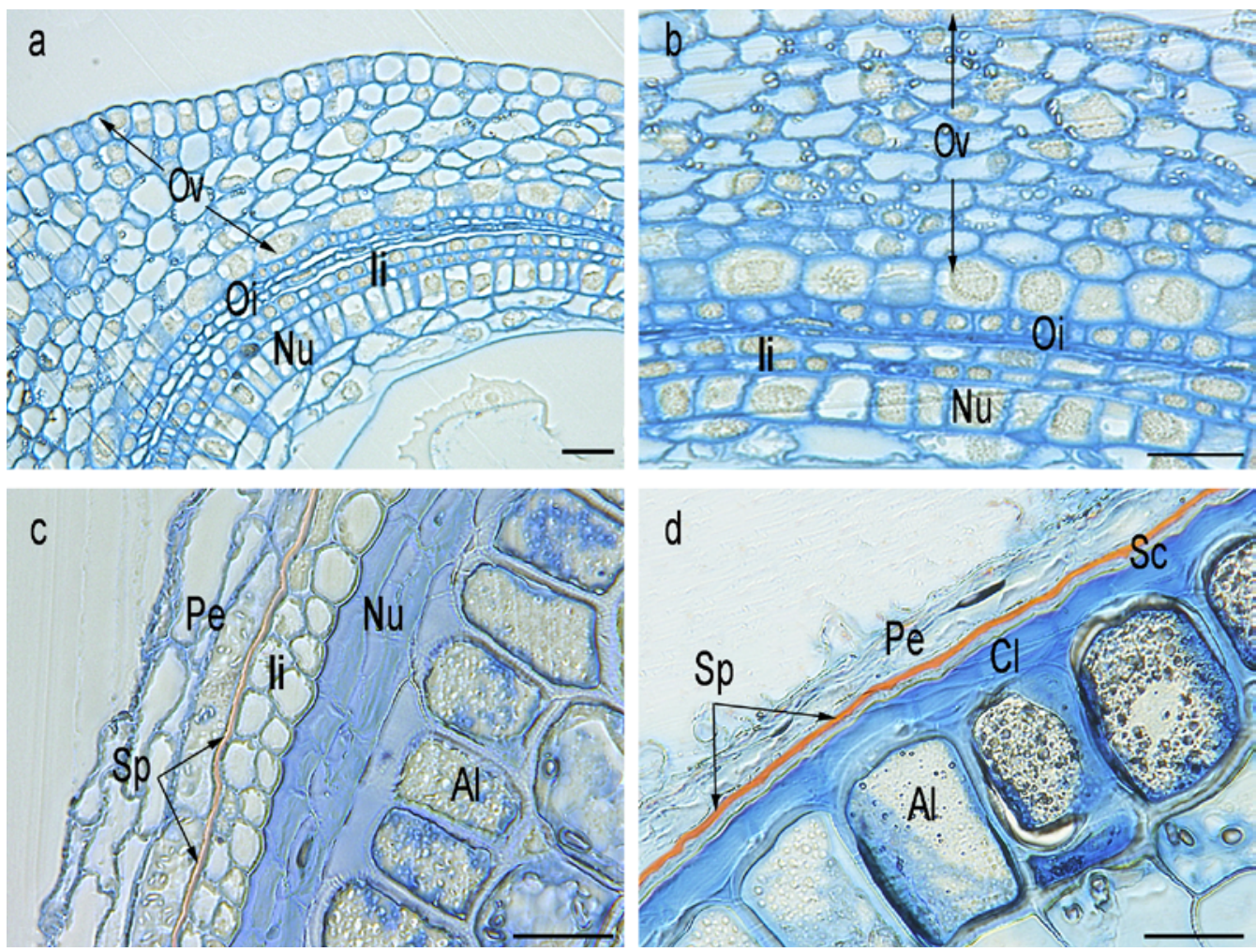

Fig. 2 LM images showing anatomical structure of cross-sections of E. sibiricus seed coat during seed development from 2 to $24 \mathrm{dpa}$. a It showed the ovary wall $(\mathrm{Ov})$, outer integument (Oi), inner integument (Ii) and the nucellus (Nu) at $2 \mathrm{dpa}$. b The outer integument had left only one layer cell. c A red line located between pericarp (Pe) and inner integument (Ii) and the aleurone cell (Al) had formed at $10 \mathrm{dpa}$. The remaining nucellus $(\mathrm{Nu})$ was stained by the aniline blue. $\mathbf{d}$ The main structure of the seed included the pericarp (Pe), the semi-permeable layer $(\mathrm{Sp})$, the seed coat $(\mathrm{Sc})$, the callose layer $(\mathrm{Cl})$ and the aleurone layer (Al) at $24 \mathrm{dpa}$. Scale bars: a,b,d $20 \mu \mathrm{m} ; \mathbf{c} 10 \mu \mathrm{m}$. 

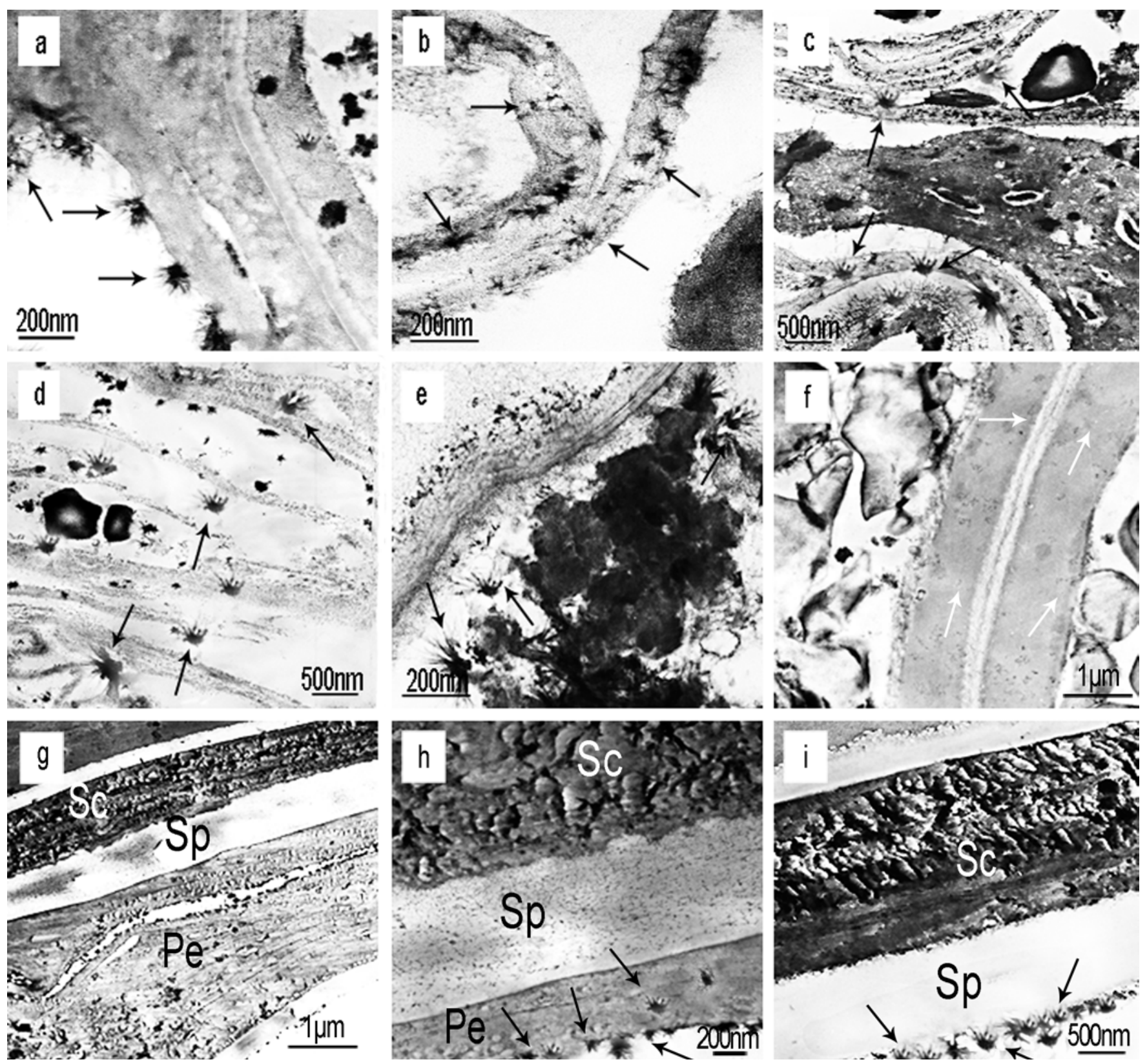

Fig. 3 TEM images of the semi-permeable layer formation in E. nutans. a,b The nucellar cells contained a large amount of lanthanum deposits, which resembled snowflakes at 2 and 4 dpa. c-e The remaining nucellus (c,d) and the aleurone cell (e) contained lanthanum deposits at 6-10 dpa. f Lanthanum was not observed between the inner integument cell walls at $12 \mathrm{dpa}$. $\mathrm{g}$ At $20 \mathrm{dpa}$, lanthanum was deposited at the pericarp (Pe). h A magnification of panel g. $\mathbf{i}$ The view of the entire seed coat (Sc) and the semi-permeable layer (Sp) at 26 dpa. The black arrows show the deposition of lanthanum, and the white arrows show the absence of lanthanum.

outer integument cells had degraded and had only left two layers of inner integument, which attached the inner layer of pericarp. The ovary wall parenchyma cells were fused while the inner cell had elongated to suffuse with the cytoplasm at $8 \mathrm{dpa}$ (Fig. 1b). Until $12 \mathrm{dpa}$, between the pericarp and inner integument, a red line, which was only stained by the Sudan III, had appeared and this red layer was the semi-permeable layer, which was checked as an amorphous membrane under the TEM (Fig. 1c). The semi-permeable layer was visible as a continuous layer on the outer periclinal walls of the inner integument. At this developmental stage, aleurone cells also had appeared and were situated next to the remainder nucellus cell wall, which was stained by aniline blue. The inner integument lost its cytoplasm and became more and more tight to form the seed coat. By $26 \mathrm{dpa}$, the nucellus cells, which had already been reduced to one layer at $8 \mathrm{dpa}$, degraded completely leaving the apparently fully developed callose layer in the seeds at full maturity. The semi-permeable layer could be easily identified and was firmly attached to the seed coat. The pericarp left only one cell layer and the seed coat lost cell form. The periclinal and anticlinal walls of the aleurone layer continued to increase in thickness while they had increased in aleurone cytoplasmic contents. The mature caryopsis coat of $E$. nutans consisted of the pericarp, the seed coat with an associated semi-permeable layer, the callose layer and the aleurone layer (Fig. 1d).

E. sibiricus had the same trend with $E$. nutans with regards to the anatomical structure of the semi-permeable layer formation. At the early stages of seed development (Fig. 2a), the caryopsis also included ovary wall cells, outer integument, inner integument and nucellus. The parenchyma cells of the ovary wall and the outer integument were fused and degraded at 6 dpa (Fig. 2b). By 10 dpa, a red layer was visible, and could be 

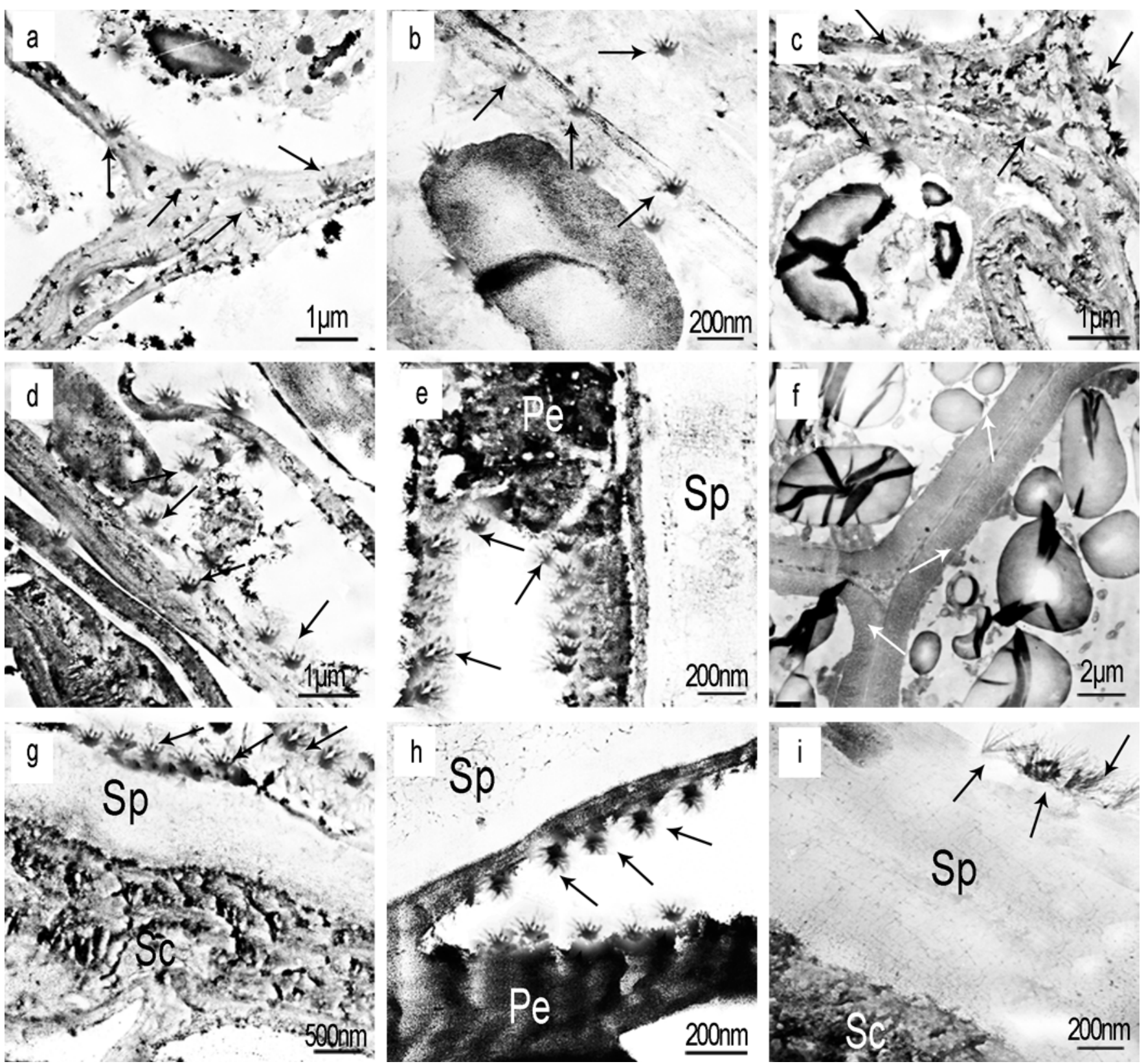

Fig. 4 TEM images of the semi-permeable layer formation in E. sibiricus. a-c Lanthanum was deposited at the nucellus cells at 2 to 6 dpa. d The inner integument was penetrated by lanthanum at $8 \mathrm{dpa}$. e Lanthanum was located at the pericarp $(\mathrm{Pe})$ and was resisted at the semi-permeable layer (Sp) at $10 \mathrm{dpa}$. $\mathrm{f}$ Lanthanum was not detected between the inner integument and the cell wall at $10 \mathrm{dpa}$. $\mathrm{g}$ At $14 \mathrm{dpa}$, lanthanum was not deposited at the seed coat (Sc), and Sp resembled a membrane structure. $\mathbf{h}$ At up to 18, lanthanum was deposited at the pericarp (Pe). i A view of the semi-permeable layer (Sp) near to the seed coat (Sc) at $24 \mathrm{dpa}$. The black arrows show the deposition of lanthanum, and the white arrows show the absence of lanthanum.

described as a continuous layer on the outer periclinal walls of the inner integument. The remaining nucellus cells lost their cell inclusion and appeared to develop a callose layer, which was stained by aniline blue (Fig. 2c). Until full maturity at 24 dpa, the structure of E. sibiricus included the pericarp, a seed coat with an associated semi-permeable layer, a callose layer and the aleurone layer (Fig. 2d).

\section{The TEM analysis of the semi-permeable layer formation}

The semi-permeable layer was identified as the position, which can inhibit the penetration of the lanthanum. In $E$. nutans at $2 \mathrm{dpa}$, lanthanum was deposited at the nucellus cell wall, and the electron micrographs revealed that the shape of the lanthanum resembled a snowflake (Fig. 3a). Lanthanum crystals accumulated in the inner seed at the preliminary developmental stages, which included 4 to $10 \mathrm{dpa}$. Black arrow indicated the lanthanum deposited in the nucellus cell wall (Fig. 3b) and the free endosperm cells (Fig. 3c). At 8 dpa, there were large amounts of lanthanum deposited at the remaining nucellus cell walls and around the starch granules (Fig. 3d). The lanthanum was mainly deposited at the intercellular air spaces of the aleurone cell at $10 \mathrm{dpa}$ (Fig. 3e). At $12 \mathrm{dpa}$, within the pericarp surrounding the inner integument, we did not detect any lanthanum ions between the two layers of the inner integument cell wall (Fig. 3f), which is indicated by the white arrow. An abundance of lanthanum was detected at the pericarp cells and near the amorphous membrane, which was located outer periclinal wall of the seed coat at $20 \mathrm{dpa}$ (Fig. 3g). By magnifying Fig. 3g, we observed the lanthanum deposited at the pericarp and the semi-permeable layer resembles a bright 


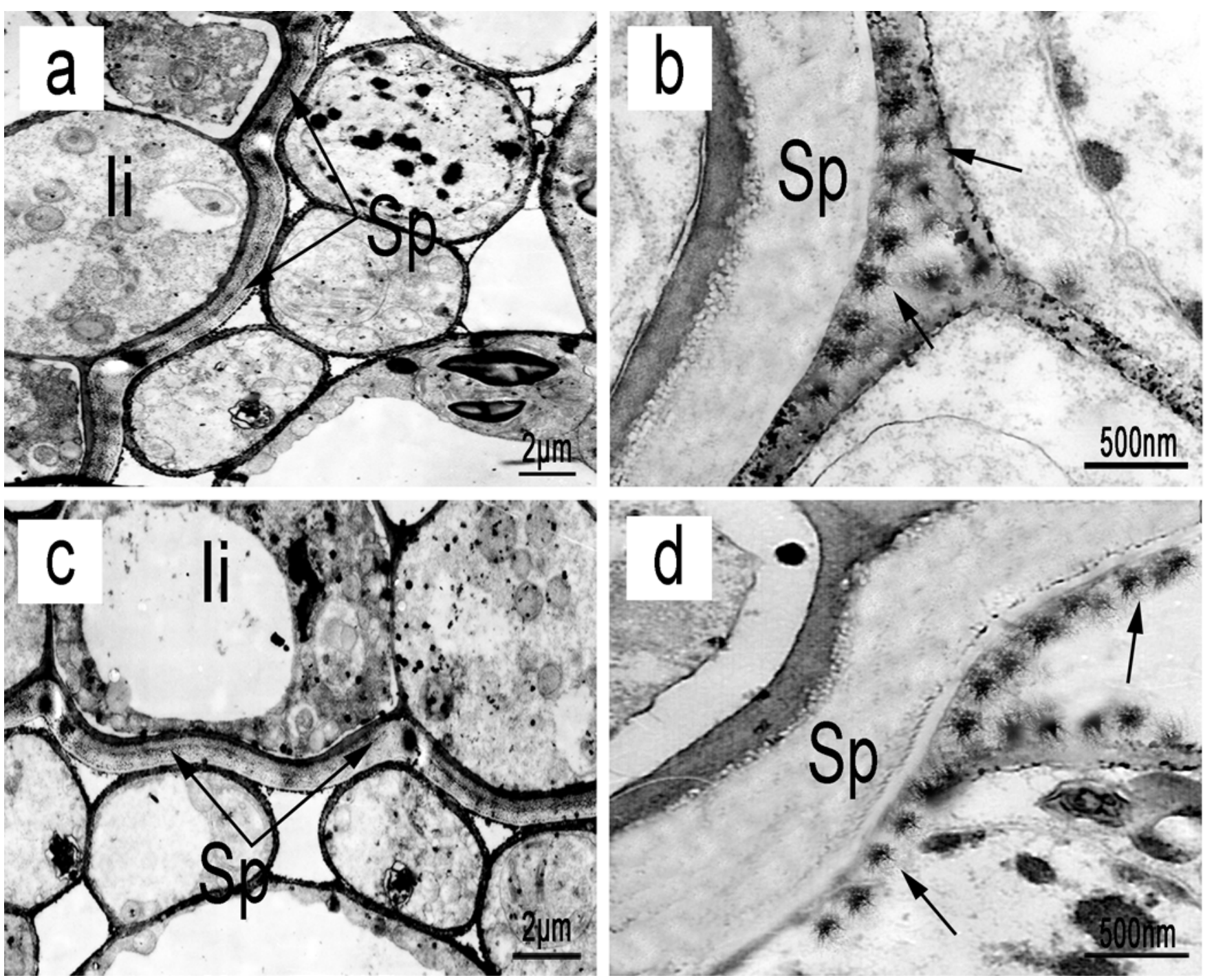

Fig. 5 TEM images showing the comparison of structure of the semi-permeable layer formation in E. nutans (a,b) and E. sibiricus (c,d). a,c Entire inner integument (Ii). b,d Amplifications of $\mathbf{a}$ and $\mathbf{c}$, respectively. Sp shows the semi-permeable layer. The arrow shows the lanthanum deposits in $\mathbf{b}$ and $\mathbf{d}$.

linear membrane structure (Fig. 3h). At a higher magnification of the seeds at $26 \mathrm{dpa}$, the amorphous membrane was observed as a continuous area in the inner region of the pericarp, which was tightly connected to the seed coat (Fig. 3i).

Common trends were observed with respect to the deposition of lanthanum in the two different types of seeds. At the early stages of $E$. sibiricus seed growth of 2 and $8 \mathrm{dpa}$, snowflakeshaped lanthanum could permeate into the nucellar cells, which was deposited in the cell walls and starch granules (Fig. 4a-c) and the inner integument cell wall (Fig. 4d). At 10 dpa (Fig. 4e), a thick periclinal wall formed that was located between the pericarp and the inner integument, and the lanthanum was blocked to penetrate into the inner integument (Fig. 4f). The arrows in Fig. 4g-i indicated the semi-permeable layer at 14, 18 and $24 \mathrm{dpa}$, which resisted the penetration of lanthanum.

In the ultrastructural investigation used for TEM, views of the entire two layers of the inner integument can be observed in Fig. 5a and Fig. 5c for E. nutans and E. sibiricus, respectively, at 12 and $10 \mathrm{dpa}$. The results showed that the outer periclinal wall of the inner integument had formed (Fig. 5b,d) to prevent the lanthanum from penetrating into the inner seed (arrow point). This layer was similar to an amorphous membrane that was firmly attached to the inner integument.
These observations showed that the timing of the formation of the semi-permeable layer was different in E. nutans and $E$. sibiricus but that the position of this membrane was the same, i.e., between the inner pericarp and the seed coat.

\section{Physiological parameters associated with seed development stages}

In E. nutans, the thousand seed weight reached a maximum of $4.0 \mathrm{~g}$ at $26 \mathrm{dpa}$, and no significant changes were observed from 24 to $30 \mathrm{dpa}$. The germination reached a maximum of $96 \%$ at $22 \mathrm{dpa}$. From 20 to $30 \mathrm{dpa}$, the germination exhibited no significant differences. The seed moisture content first increased from $51 \%$ to $60 \%$ between 2 and $8 \mathrm{dpa}$, and then declined rapidly during the next $22 \mathrm{~d}$ (Fig. 6a) to reach a minimum of $19 \%$ at $30 \mathrm{dpa}$. Based on the thousand seed weight and germination, the E. nutans seeds reached physiological maturity at $26 \mathrm{dpa}$.

Seeds at different developmental stages were immersed in distilled water for $24 \mathrm{~h}$. The electrical conductivity of the seed leachate and the imbibition rate decreased and the permeability of seed was reduced with seed maturity. Between 2 and 12 dpa, the electrical conductivity decreased from $463 \mu \mathrm{s} \mathrm{cm}^{-1} \mathrm{~g}^{-1}$ to $138 \mu \mathrm{sm}^{-1} \mathrm{~g}^{-1}$ and a significant reduction in these values occurred prior to $12 \mathrm{dpa}$ (Fig. 6b). After $12 \mathrm{dpa}$, the electrical conductivity exhibited only relatively steadily. The imbibition 
rate decrease from $138 \%$ to $62 \%$ at 2 to $16 \mathrm{dpa}$ and then had small changes that were not significant.

The seed moisture content increased slightly between 2 and $10 \mathrm{dpa}$ from $53 \%$ to $64 \%$ and then declined during the next 20 days to reach a minimum of $16 \%$ at $30 \mathrm{dpa}$ in E. sibiricus (Fig. 7a). The thousand seed weight reached a maximum of $4.1 \mathrm{~g}$ at $24 \mathrm{dpa}$, and no significant differences were observed from 24 to $30 \mathrm{dpa}$. The germination reached $92 \%$ at $22 \mathrm{dpa}$ (Fig. 7a). Therefore, the E. sibiricus seeds reached physiological maturity at $24 \mathrm{dpa}$.

The electrical conductivity declined sharply from $443 \mu \mathrm{s} \mathrm{cm}^{-1}$ $\mathrm{g}^{-1}$ to $167 \mu \mathrm{sm}^{-1} \mathrm{~g}^{-1}$ between 2 to $10 \mathrm{dpa}$ and then declined slowly. The imbibition rate decreased significantly during 2 to 14 dpa (Fig. 7b).

\section{Discussion}

The mature seeds of E. nutans and E. sibiricus contained a semi-permeable layer, which was similar in both species: the layer was typically amorphous, highly compact, and easily distinguished from the seed coat and pericarp under the LM and TEM observation (Fig. 1c, Fig. 2c, Fig. 3h, Fig. 4i, Fig. 5b,d). The shape of this layer was similar to the observations by Beresniewicz et al. [4] for leek (Allium porrum L.), onion (Allium cepa L.), tomato and pepper seeds, although the location of the semi-permeable layer was located at the innermost layer of the seed coat and directly adjacent to the endosperm.
However, in this present study, the semi-permeable layer was shown to be located at the outermost layer of the seed coat and was firmly attached to it. The location of this layer varied in seeds of different species. In barley, wheat (Triticum aestivum L.), rye (Secale cereal L.) $[5,21,36]$, and corn [24] were found that the semi-permeable layer was on the seed coat, although the layer was not shown to be located in a specific site within the inner or outer part of the seed coat. Hill and Taylor [11] believe that lettuce seeds have an endospermic semi-permeable layer, which is around the embryo, forming a permeable barrier tissue. The endosperm of the castor seed prevents the penetration of fluorescent dye, indicating the presence of an endosperm semi-permeable layer [17]. In muskmelon [19] and cucumber [18], the semi-permeable layer was present in the perisperm-endosperm envelope. But in Sudan grass [13], the semi-permeable layer was located at the inner aleurone layer, connected to the undifferentiated cells.

The formation of the semi-permeable layer was accompanied by seed development. E. nutans formed this layer at $12 \mathrm{dpa}$ (Fig. 1c), whereas in E. sibiricus occurred at 10 dpa (Fig. 2c). The result was different from other species. Yim and Bradford [19] had reported that in muskmelon seed, the semi-permeable layer formed at $40 \mathrm{dpa}$, whereas in cucumber seeds [18], this layer formed at $45 \mathrm{dpa}$. In Sudan grass, the semi-permeable layer emerged at $16 \mathrm{dpa}$ [25]. Together with the physiological maturity parameters, the conductivity provided an indication of the permeability of caryopsis coat. After the semi-permeable layer formed, the conductivity showed no significant changes
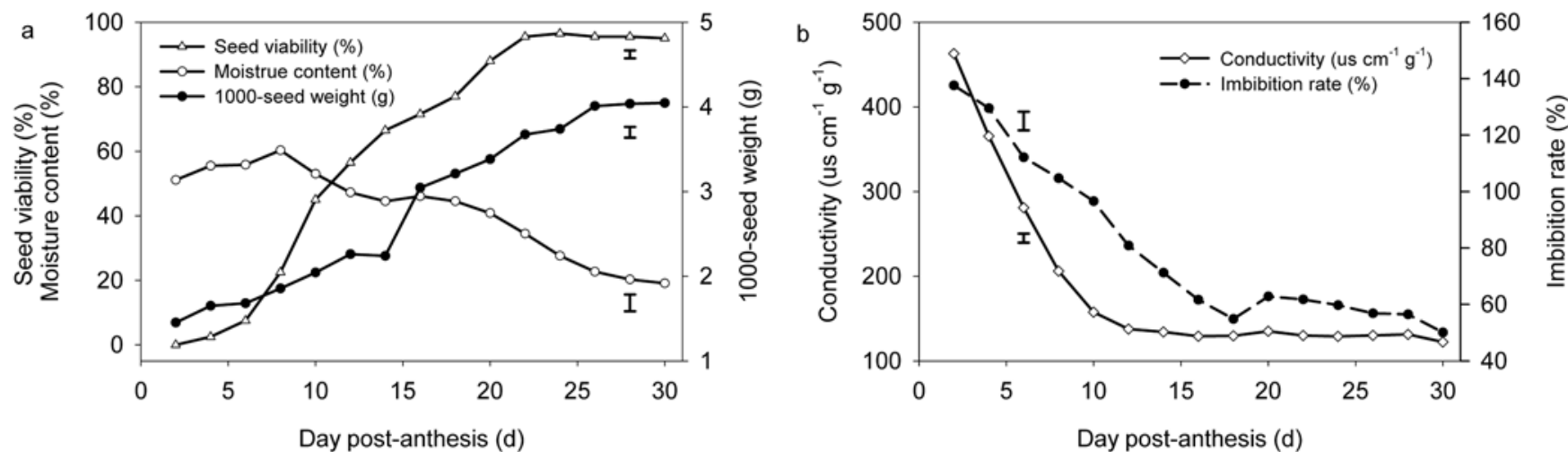

Fig. 6 Physiological parameters of E. nutans. a Seed moisture content (seed moisture content), viability (germination) and weight (thousand seed weight) at different development stages. $\mathbf{b}$ Seed conductivity and imbibition rate at different development stages. The bars denote the LSD values for each item.
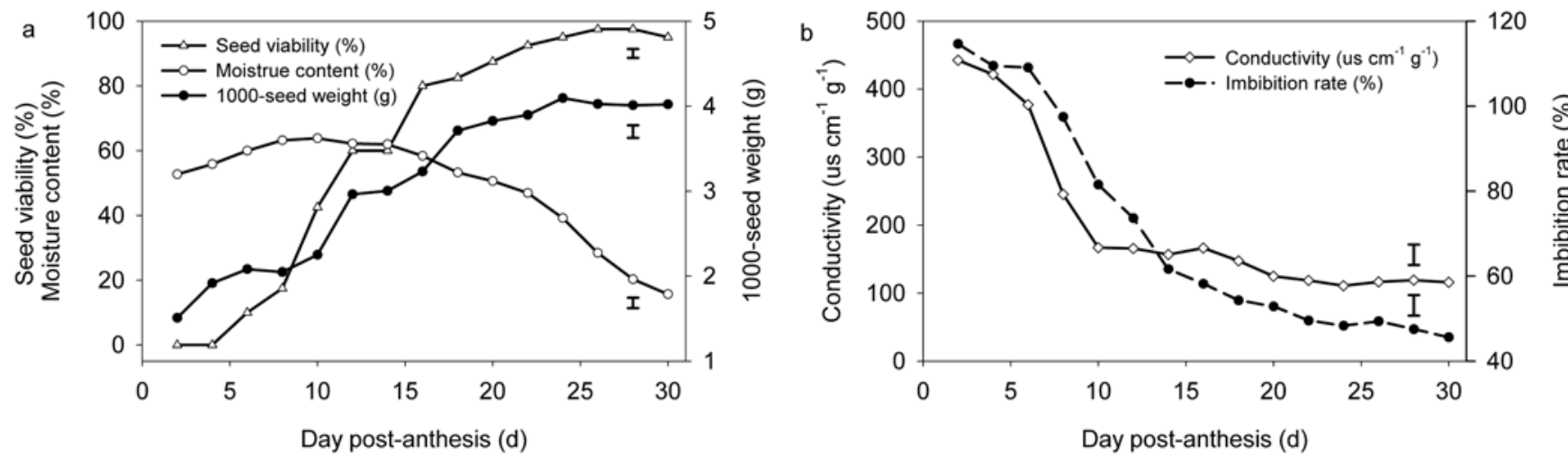

Fig. 7 Physiological parameters of E. sibiricus. a Seed moisture content (seed moisture content), viability (germination) and weight (thousand seed weight) at different development stages. b Seed conductivity and imbibition rate at different development stages. The bars denote the LSD values for each item. 
(Fig. 6b, Fig. 7b). This layer resisted the outward diffusion of the seeds' contents, therefore, the conductivity indicated the formation of the semi-permeable layer. This result was consistent with the anatomical results showing that the semi-permeable layer of E. nutans and E. sibiricus formed at 12 and $10 \mathrm{dpa}$, respectively.

The seed coat usually developed from one or two integuments, and the mature caryopsis coat included the pericarp, the seed coat and the nucellus [26]. At seed maturity, much of the integumentary tissue may be degenerated and absorbed by other developing tissues [26]. Therefore, it was important to identify the specific parts that had participated in the formation of the semi-permeable layer. In barley, Collins [21] thought that the integumentary system as the role of semi-permeable properties but Brown [37] indicated that the epidermis of the nucellus had formed the semi-permeable layer in barley. In the caryopsis of maize, the surface of both the inner integument and the epidermis of the nucellus became physically united and then formed the semi-permeable layer [24]. In muskmelon seeds, an extracellular layer composed primarily of callose was entirely responsible for the semi-permeable properties of the endosperm envelope [19]. However, in cucumber seeds, the semi-permeable layer appeared to differentiate in the epidermis of the multilayered nucellus [18]. But in tall wheatgrass [Agropyron elongata. (Host) P. Beauv.] [38] and buffalograss [Buchloe dactyloides (Nutt.) Engelm.] [39], the outer integument had formed the semi-permeable layer. In our experiment, the cells differentiated and fused as the seeds developed, and the outer periclinal walls of the inner integument formed a semipermeable layer (Fig. 5). TEM (Fig. 3f, Fig. 4e) showed that this thickened periclinal wall prevented lanthanum penetration into the inner seeds. Therefore, this cell wall was responsible for the semi-permeability of the seed coat. The result was consistent with a report by Stiles [6] that indicated that the thickened wall might play an important role in determining the permeability.

Based on the anatomical structure of the caryopsis coat, it was evident that during the seed development, the outer integument disappeared, whereas the inner integument developed into a seed coat that was difficult to differentiate from the pericarp. The structures of these two types of seeds were similar to the caryopsis of Triticum [26], which included a pericarp, seed coat and aleurone layer. However, prior to the physiological maturity of the seed, the semi-permeable layer had appeared (Fig. 1, Fig. 2). This result was important for the growth of seed. As the seed develops, the contents and nutrient would continue to increase until the seed reached its maximum weight [40]. The semi-permeable layer may prevent nutrients from being lost to the environment when the plant encounters poor growth conditions. Thus, this layer can promote safe and healthy growth in seeds. Furthermore, the semi-permeability would prevent the loss of solutes to the environment until the embryo was capable of resorbing them prior to the initiation of radicle growth [19].

In conclusion, the semi-permeable layer existed in the seed coats of E. nutans and E. sibiricus. The semi-permeable layer was located at the outermost layer of the seed coat and was connected to the pericarp. As demonstrated by the anatomical observations, the semi-permeable layer was formed by the outer periclinal walls of the inner integument at 12 to $10 \mathrm{dpa}$ and was similar between the two species: typically amorphous, highly compact, but easily distinguished from the pericarp and testa. Based on comparisons with physiological experiments, the formation time of the semi-permeable layer occurred prior to the seed physiological maturity.

\section{Acknowledgments}

We are grateful for the financial support provided by the Natural Science Foundation of China (No. 30771532) and the National Basic Research Program of China (973 Program, No. 2007CB108904). We also gratefully acknowledge the editor and two anonymous reviewers for their valuable comments and constructive suggestions.

\section{Authors' contributions}

The following declarations about authors' contributions to the research have been made: designed the experiments: YW, JZ; analyzed the experimental data: JZ; wrote the paper: JZ, YW, JT.

\section{References}

1. Windsor JB, Symonds VV, Mendenhall J, Lloyd AM. Arabidopsis seed coat development: morphological differentiation of the outer integument. Plant J. 2000;22(6):483-493. http://dx.doi.org/10.1046/j.1365-313x.2000.00756.x

2. Boesewinkel F, Bouman F. The seed: structure and functions. In: Kigel J, Galili G, editors. Seed development and germination. New York NY: Marcel Dekker; 1995. p. 1-24.

3. Amritphale D, Ramakrishna P, Singh B, Sharma SK. Solute permeation across the apoplastic barrier in the perisperm-endosperm envelope in cucumber seeds. Planta. 2010;231(6):1483-1494. http://dx.doi.org/10.1007/ s00425-010-1146-5

4. Beresniewicz MM, Taylor AG, Goffinet MC, Terhune BT. Characterization and location of a semipermeable layer in seed coats of leek and onion (Liliaceae), tomato and pepper (Solanaceae). Seed Sci Technol. 1995;23(1):123-134.

5. Brown AJ. On the existence of a semi-permeable membrane enclosing the seeds of some of the Gramineae. Ann Bot. 1907;21(1):79-87.

6. Stiles W. Permeability. New Phytol. 1922;21(2):49-57. http://dx.doi. org/10.1111/j.1469-8137.1922.tb07587.x

7. Wolfe HS. Absorption of water by barley seeds. Bot Gaz. 1926;82(1):89. http://dx.doi.org/10.1086/333635

8. Prutsch J, Schardt A, Schill R. Adaptations of an orchid seed to water uptake and storage. Plant Syst Evol. 2000;220(1-2):69-75. http://dx.doi. org/10.1007/BF00985371

9. Salanenka YA, Goffinet MC, Taylor AG. Structure and histochemistry of the micropylar and chalazal regions of the perisperm-endosperm envelope of cucumber seeds associated with solute permeability and germination. J Am Soc Hortic Sci. 2009;134(4):479-487.

10. Thornton ML. Seed dormancy in watermelon Citrullus vulgaris Shrad. Proc Assoc Seed Anal. 1968;58:80-84.

11. Hill HJ, Taylor AG. Relationship between viability, endosperm integrity, and imbibed lettuce seed density and leakage. Hort Sci. 1989;24(5):814-816.

12. Welbaum GE, Bradford KJ. Water relations of seed development and germination in muskmelon (Cucumis melo L.) IV. Characteristics of the perisperm during seed development. Plant Physiol. 1990;92(4):1038-1045. http://dx.doi.org/10.1104/pp.92.4.1038

13. Yan XJ, Wang YR. Location of semipermeable layer and permeability of seed in Sorghum sudanense. Acta Prataculturae Sin. 2008;17(5):54-59.

14. Zhou J, Wang YR. Research advances in semi-permeable layer of seed. Acta Bot Boreal-Occident Sin. 2012;32(9):1928-1934.

15. Beresniewicz MM, Taylor AG, Goffinet MC, Koeller WD. Chemical nature of a semipermeable layer in seed coats of leek, onion (Liliaceae), tomato and pepper (Solanaceae). Seed Sci Technol. 1995;23(1):135-145.

16. Taylor AG, Beresniewicz MM, Goffinet MC. Semipermeable layer in seeds. In: Ellis RH, Black M, Murdoch AJ, Hong TD, editors. Basic and applied 
aspects of seed biology. Dordrecht: Springer Netherlands; 1997. p. 429-436. (Current plant science and biotechnology in agriculture).

17. Salanenka YA, Taylor AG. Uptake of model compounds by soybean, switchgrass and castor seeds applied as seed treatments. In: Seed production and treatment in a changing environment: proceedings of an international symposium, Wishaw, Warwickshire, UK, 24-25 February 2009. Hampshire: BCPC Publications; 2009. p. 76-81.

18. Ramakrishna P, Amritphale D. The perisperm-endosperm envelope in Cucumis: structure, proton diffusion and cell wall hydrolysing activity. Ann Bot. 2005;96(5):769-778. http://dx.doi.org/10.1093/aob/mci234

19. Yim KO, Bradford KJ. Callose deposition is responsible for apoplastic semipermeability of the endosperm envelope of muskmelon seeds. Plant Physiol. 1998;118(1):83-90. http://dx.doi.org/10.1104/pp.118.1.83

20. Simpson GM. Seed dormancy in grasses. Cambridge: Cambridge University Press; 1990.

21. Collins EJ. The structure of the integumentary system of the barley grain in relation to localized water absorption and semi-permeability. Ann Bot. 1918;32(3):381-414.

22. Brown R. The absorption of water by seeds of Lolium perenne (L.) and certain other Gramineae. Ann Appl Biol. 1931;18(4):559-573. http:// dx.doi.org/10.1111/j.1744-7348.1931.tb02325.x

23. Harrington GT, Crocker W. Structure, physical characteristics, and composition of the pericarp and integument of Johnson grass seed in relation to its physiology. J Agric Res. 1923;23(3):193-222.

24. Johann H. Origin of the suberized semipermeable membrane in the caryopsis of maize. J Agric Res. 1942;64(5):275-282.

25. Yan XJ. Study on microstructure and location of semi-permeable layer in several grass species seed [Master thesis]. Lanzhou: Lanzhou University; 2008.

26. Fahn A. Plant anatomy. 3rd ed. Oxford: Pergamon Press; 1982.

27. Lu GP, Nie B. Field evaluation of Elymus nutans under alpine grassland conditions. Pratacultural Sci. 2002;19(9):13-15.

28. Makarenko SP, Konstantinov YM, Khotimchenko SV, Konenkina TA,
Arziev AS. Fatty acid composition of mitochondrial membrane lipids in cultivated (Zea mays) and wild (Elymus sibiricus) grasses. Russ J Plant Physiol. 2003;50(4):487-492. http://dx.doi.org/10.1023/A:1024716606132

29. Liu Y, Horisawa S, Mukohata Y. Effect of seed coating on plant growth and soil conditions: a preliminary study for restoration of degraded rangeland in the Qinghai-Tibetan Plateau, China. Grassl Sci. 2010;56(3):145-152. http://dx.doi.org/10.1111/j.1744-697X.2010.00187.x

30. Kuroiwa T, Fujie M, Mita T, Kuroiwa H. Application of embedding of samples in Technovit 7100 resin to observations of small amounts of DNA in the cellular organelles associated with cytoplasmic inheritance. Appl Fluoresc Tech. 1991;3:23-25.

31. Zheng GC. Biological microscopy techniques. Beijing: People’s Education Press; 1993.

32. Sulborska A, Weryszko-Chmielewska E. Anatomy and ultrastructure of floral nectary of Inula helenium L. (Asteraceae). Acta Soc Bot Pol. 2007;76(3):201-207.

33. Administration of Quality and Technical Supervision of the People Republic of China. Rules for forage seed testing-sampling (GB/T 2930.1). Beijing: Standards Press of China; 2001.

34. ISTA (International Seed Testing Association). International rules for seed testing. Seed Sci Technol. 1993;21 suppl:141-146.

35. Hampton JG, TeKrony DM. Handbook of vigour test methods. Zurich: International Seed Testing Association; 1995.

36. Kotowski F. Semipermeability of seed coverings and stimulation of seeds. Plant Physiol. 1927;2(2):177-186. http://dx.doi.org/10.1104/pp.2.2.177

37. Brown AJ. The selective permeability of the coverings of the seeds of Hordeum vulgare. Proc R Soc Lond B Biol Sci. 1909;81(546):82-93. http:// dx.doi.org/10.1098/rspb.1909.0009

38. Thornton ML. Seed dormancy in tall wheatgrass (Agropyron elongatum). Proc Assoc Seed Anal. 1966;56:116-119.

39. Thornton ML. Seed dormancy in buffalo grass (Buchloe dactyloides). Proc Assoc Seed Anal. 1966;56:120-123.

40. Yan QC. Seed. Beijing: China Agricultural Press; 2001. 